\title{
Insights into female sperm storage from the spermathecal fluid proteome of the honeybee Apis mellifera Boris Baer ${ }^{* \dagger}$, Holger Eubel ${ }^{*}$, Nicolas L Taylor ${ }^{*}$, Nicholas O'Toole ${ }^{\ddagger}$ and A Harvey Millar*
}

\begin{abstract}
Addresses: *ARC Centre of Excellence in Plant Energy Biology, The University of Western Australia, Stirling Hwy, Crawley WA 6oo9, Australia. ${ }^{+}$Centre for Evolutionary Biology, School of Animal Biology, The University of Western Australia, Stirling Hwy, Crawley WA 6oo9, Australia. ${ }^{\ddagger}$ Centre of Excellence for Computational Systems Biology, The University of Western Australia, Stirling Hwy, Crawley WA 6oo9, Australia.
\end{abstract}

Correspondence: Boris Baer. Email: bcbaer@cyllene.uwa.edu.au

Published: 18 June 2009

Genome Biology 2009, 10:R67 (doi:10.1 186/gb-2009-10-6-r67)

The electronic version of this article is the complete one and can be found online at http://genomebiology.com/2009//0/6/R67
Received: 20 February 2009

Revised: 6 May 2009

Accepted: 18 June 2009

(C) 2009 Baer et al.; licensee BioMed Central Ltd.

This is an open access article distributed under the terms of the Creative Commons Attribution License (http://creativecommons.org/licenses/by/2.0), which permits unrestricted use, distribution, and reproduction in any medium, provided the original work is properly cited.

\begin{abstract}
Background: Female animals are often able to store sperm inside their body - in some species even for several decades. The molecular basis of how females keep non-own cells alive is largely unknown, but since sperm cells are reported to be transcriptionally silenced and, therefore, limited in their ability to maintain their own function, it is likely that females actively participate in sperm maintenance. Because female contributions are likely to be of central importance for sperm survival, molecular insights into the process offer opportunities to observe mechanisms through which females manipulate sperm.

Results: We used the honeybee, Apis mellifera, in which queens are highly polyandrous and able to maintain sperm viable for several years. We identified over a hundred proteins representing the major constituents of the spermathecal fluid, which females contribute to sperm in storage. We found that the gel profile of proteins from spermathecal fluid is very similar to the secretions of the spermathecal gland and concluded that the spermathecal glands are the main contributors to the spermathecal fluid proteome. A detailed analysis of the spermathecal fluid proteins indicate that they fall into a range of different functional groups, most notably enzymes of energy metabolism and antioxidant defense. A metabolic network analysis comparing the proteins detected in seminal fluid and spermathecal fluid showed a more integrated network is present in the spermathecal fluid that could facilitate long-term storage of sperm.
\end{abstract}

Conclusions: We present a large-scale identification of proteins in the spermathecal fluid of honeybee queens and provide insights into the molecular regulation of female sperm storage.

\section{Background}

Sperm storage by females is widespread throughout the animal kingdom $[1,2]$ but amazingly little is known about how females are able to keep sperm cells viable over prolonged periods of time. In many species, females provide specialized morphological structures for sperm storage often known as spermathecae [3]. Females 'interact' with and 'sustain' sperm that are stored in these structures through glandular secre- 
tions, produced, for example, by the spermathecal glands [4]. These secretions contain proteins, metabolites and other chemicals in the honeybee Apis mellifera [5] and spermathecal fluid has recently been shown to maintain sperm viability $[6,7]$. Several proteins have been proposed to be responsible for this effect, such as the glycolytic enzyme triosphosphate isomerase [5] and a number of antioxidant defense enzymes [8]. In addition, high $\mathrm{K}^{+}$concentrations and the high $\mathrm{pH}$ of the spermathecal fluid have been proposed to lower the metabolic rate of sperm in storage $[5,9,10]$. However, despite the spermatheca containing 5 to $10 \mathrm{mg}$ of protein/ $\mathrm{ml}$ [5], no systematic analysis of these female derived proteins has so far been conducted. As a consequence, our knowledge about the biochemical and physiological mechanisms that maintain sperm viability or the physiological costs associated with sperm storage are extremely limited [11]. Furthermore, females have been hypothesized to bias paternity outcomes by manipulating sperm in storage [12]. Consequently, sexual selection [13] may influence the female contributions towards stored sperm as well.

The study of male contributions towards sperm, such as seminal fluids or male accessory gland secretions, has received much more attention [14-16]. Males transfer a complex mixture of components to the female along with sperm [13,17-21], which have multiple effects on sperm viability or female physiology $[6,7]$ but some of these components also seem to be agents of sexual conflict [22-25]. It seems reasonable to assume that females have also evolved a complementary arsenal of components to support and manipulate sperm. This makes detailed studies of female sperm storage physiology and its interactions with sperm and/or seminal fluid timely. A crucial step to understand female influence on stored sperm is to identify the components provided by the female, and proteomic technologies offer the opportunity to investigate the female's arsenal.

Social hymenopteran insects (the bees, ants and wasps) are interesting model systems to study sperm storage by females because several species have taken sperm storage to spectacular extremes $[11,26,27]$. This can be seen in terms of both the total number of sperm stored as well as the efficiency by which sperm are kept alive over prolonged periods of time [28]. A phenomenon common to many social hymenopteran insects is that queens only copulate during a brief period early in life $[16,29,30]$. In the absence of re-mating later in life, queens acquire and store a lifetime supply of sperm that often fixes the upper limit of a colony's size, longevity and fitness. Apart from the total number of initially stored sperm, queen lifetime fecundity is also influenced by her efficiency to keep sperm viable. Some social insect queens can not only live for several decades [26,31], but they also maintain colonies of several million workers [11,30,32]. Selection is therefore expected to have maximized storage efficiency of sperm number [28] and sperm survival and minimized sperm number used per egg fertilization. Sperm storage induces costs for the female that are known to trade off with other female life history traits in leaf cutter ants [11] and bumblebees [33]. Finally, in polyandrous species, ejaculates of several males can coexist within the spermatheca for years, but it remains to be investigated whether sperm competition or cryptic female choice occurs whilst sperm is in storage [29].

We have used the honeybee, $A$. mellifera, and present a proteomic identification of the female's contribution towards sperm by identifying proteins that females provide to sperm in storage. Honeybee queens are efficient sperm storers that initially store around 6 million sperm for up to 7 years, giving them an estimated potential to sire up to 1.7 million offspring (see [29] for a review on the honeybee mating system). Consequently, spermathecal fluid components are expected to maximize the survival of large numbers of sperm. Furthermore, honeybee queens are highly polyandrous and store sperm from several males. Consequently, females could use sperm storage to manipulate sperm and, thus, manipulate paternity success. An additional advantage of honeybees as a model system is that the availability of the honeybee genome sequence [34] allows the use of tandem mass spectrometry (MS/MS) to identify proteins $[19,20,35]$. We here identify the spermathecal fluid proteome of honeybee and compare it to recently published proteomic profiles of sperm and seminal fluid $[19,20]$ in order to understand the specific female contribution to sperm in storage.

\section{Results}

The proteins of spermathecal fluid collected from dissected spermathecae were separated by one-dimensional SDSPAGE (Figure 1). We compared this profile to extracted spermathecal wall proteins, hemolymph and sperm. In each case the protein profiles were distinct, showing that separation of these protein subsets could be achieved by our dissection and extraction protocols ([19] and data not shown). Protein profiles of spermathecal fluid were visually inspected on a total of 11 one-dimensional gels using 12 independent biological replicates for mated and 4 independent biological replicates for virgin queens. We found that specific protein profiles for spermathecal fluid can be consistently reproduced (Figure 1), in both technical and biological replicates and resemble those found in earlier studies [5,7]. Modifications of our standardized extraction protocol resulted in no obvious abundance changes of protein profiles on the gels, indicating that our collection method is a reliable way to sample spermathecal fluid. We found a large overlap in the spermathecal fluid protein band profiles of mated and virgin queens (Figure 2). Furthermore, the protein profile of the spermathecal gland secretions is very similar to that of the spermathecal fluid, both for mated and virgin queens (Figure 2). The protein profiles of spermathecal fluid were very different from that of seminal fluid isolated from male ejaculates (Figure 2). 


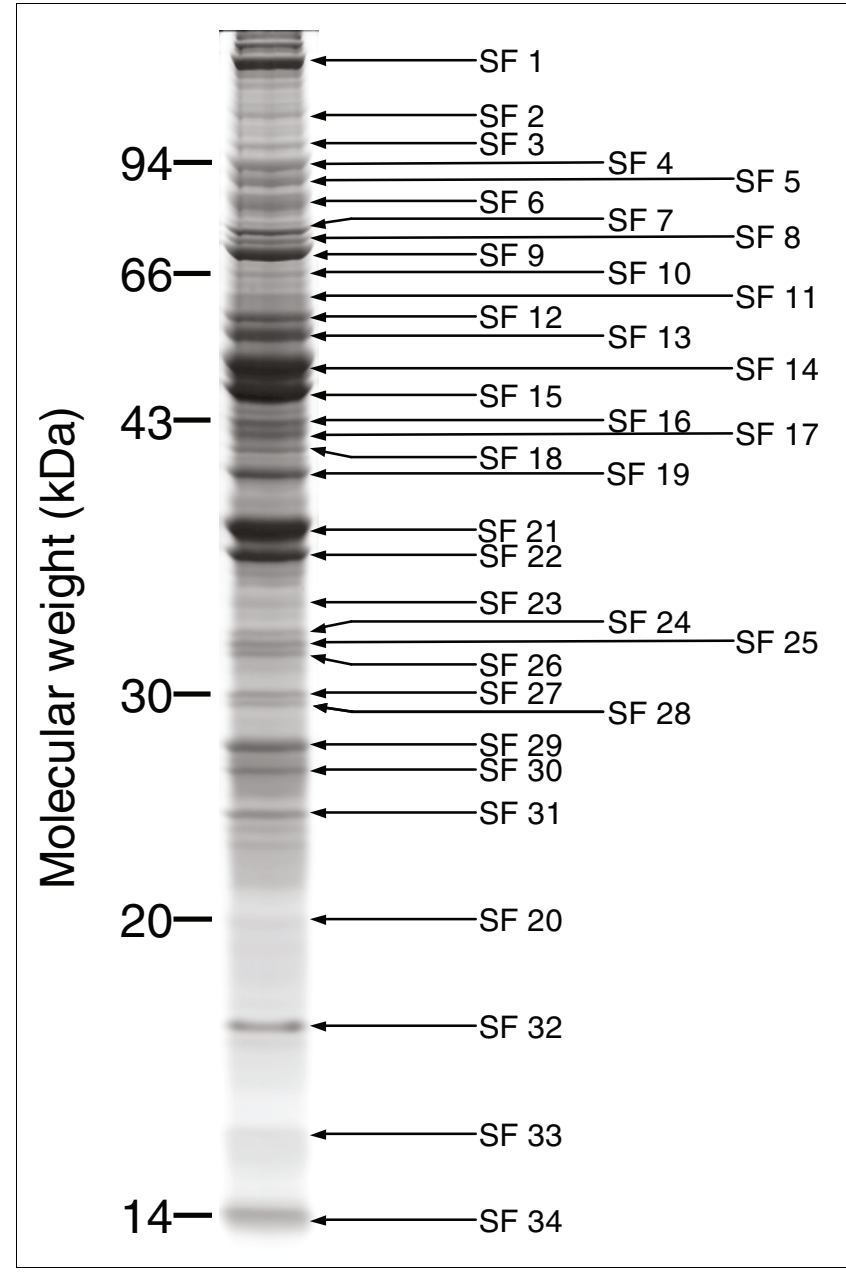

Figure I

SDS-PAGE gel separation of spermathecal fluid proteins. A colloidal Coomassie blue stained gel showing a representative protein profile of spermathecal fluid. A total of $50 \mu \mathrm{l}$ of spermathecal fluid (SF) extract was loaded on the gel. Thirty-four protein bands, as indicated by arrows, were excised for protein identification. An overview of significant protein identifications for these bands is given in Additional data file I.

To identify the most abundant proteins present in the spermathecal fluid, we ran a total of four mass spectrometry analyses from four independent biological samples. Two sets of analyses were performed, one based on in-gel digested bands of one-dimensional SDS-PAGE (Figure 1) and a second based on liquid chromatography (LC)-MS/MS analysis of total protein tryptic digests. The latter were nested experiments each consisting of six LC-MS/MS experiments performed in series, with the peptides identified in each run excluded from the subsequent analysis to improve the depth of analysis (see Materials and methods).

A summary of all significant protein identifications is given in Table 1 (protein match data are presented in Additional data file 1). Our final analysis resulted in the identification of 122 different proteins across the four spermathecal fluid samples.

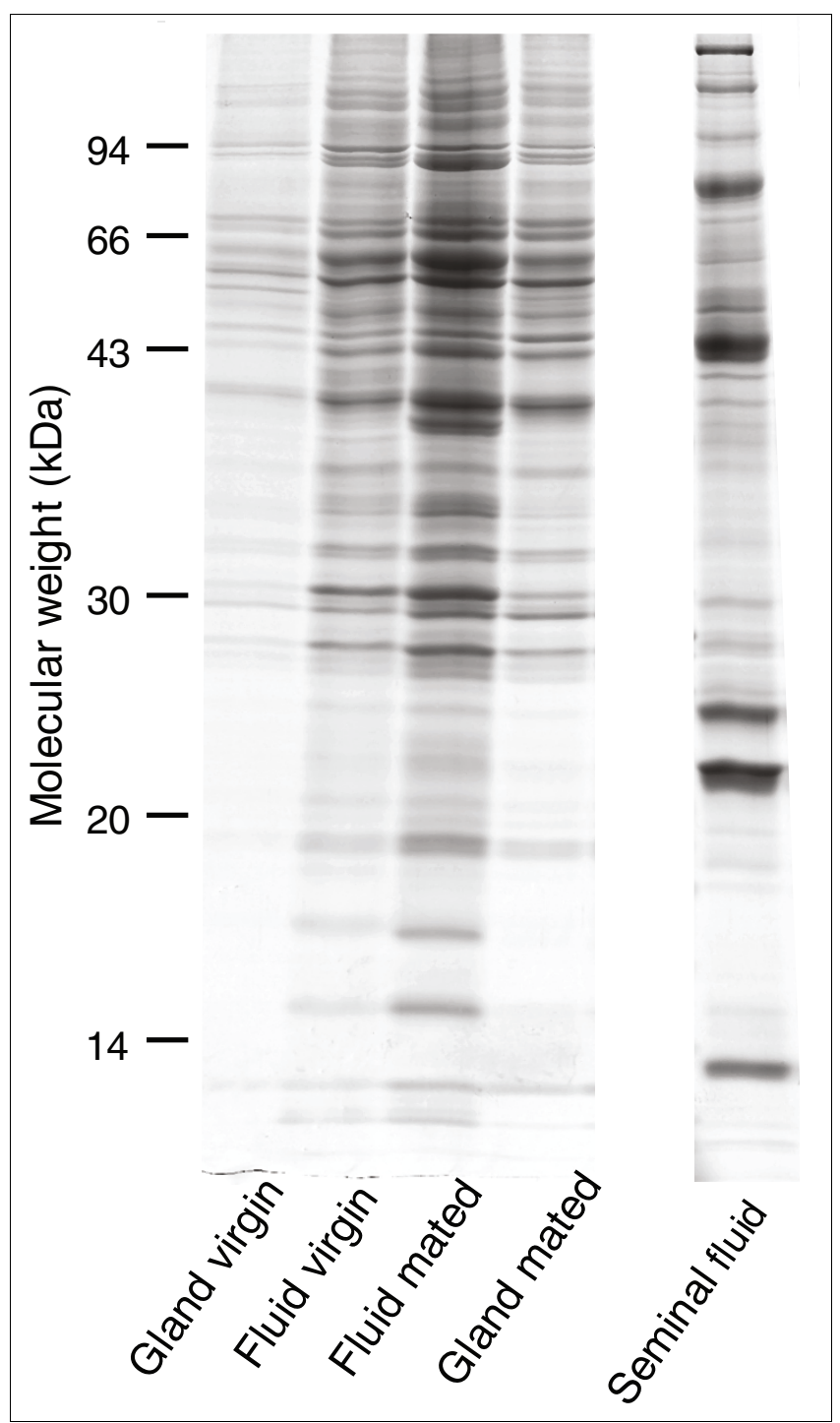

Figure 2

Spermathecal gland and spermathecal fluid proteins in mated and virgin queens. Colloidal Coomassie blue stained gel lanes showing representative protein profiles of spermathecal fluid and spermathecal gland secretions from virgin and mated queens and seminal fluid. A total of $8 \mu \mathrm{l}$ of fluid extracts from the spermathecal samples and $16 \mu \mathrm{l}$ of the seminal fluid sample were loaded on the gels.

This set of proteins included molecular chaperones, an array of enzymes involved in energy and amino acid metabolism, antioxidant enzymes, proteins involved in signaling pathways, structural proteins, and a range of proteins with unknown functions (Table 2).

We compared our list of 122 spermathecal proteins with the reported abundant proteins from bee sperm samples [19]; we found that only 10 (8\%) proteins were detected in both the spermathecal fluid and this list of sperm proteins (Figure 3; Additional data file 1). We also detected five of these ten sperm proteins in the spermathecal fluid of virgin queens, so 
Table I

Proteins in honeybee queen spermathecal fluid

\begin{tabular}{|c|c|c|c|c|c|c|c|}
\hline \multirow[b]{2}{*}{ PreRelease 2 accession } & \multicolumn{2}{|r|}{ Mated } & \multirow{2}{*}{$\frac{\text { Virgin }}{\text { LC MS/MS }}$} & \multirow[b]{2}{*}{ Seminal fluid } & \multirow[b]{2}{*}{ Sperm } & \multirow[b]{2}{*}{ Pred. secret. } & \multirow[b]{2}{*}{ Protein functional description } \\
\hline & Gel & $\mathrm{LC} M S / M S$ & & & & & \\
\hline GBI0467-PA & $x$ & $x$ & & $x$ & & & Aspartate aminotransferase 2 precursor \\
\hline GBI0973-PA & & $x$ & $\mathrm{x}$ & $x$ & & & Arginine kinase \\
\hline GBI5049-PA & & & $x$ & & & & Delta-I-pyrroline-5-carboxylate synthetase \\
\hline GBI5I7I-PA & $x$ & $x$ & & & $x$ & & Ornithine aminotransferase precursor \\
\hline GBI6218-PA & & & $x$ & & & & Proline oxidase \\
\hline GBI764I-PA & $x$ & $x$ & $x$ & & & & Alanine aminotransferase 2 \\
\hline GBI8844-PA & $x$ & $x$ & $x$ & & & & Glutamate oxaloacetate transaminase I \\
\hline GBI0I33-PA & $x$ & $\mathrm{x}$ & & & & & Superoxide dismutase \\
\hline GBI0498-PA & $x$ & $x$ & $x$ & & & & Peroxiredoxin \\
\hline GBI2029-PA & $x$ & & & & & & Glyoxalase domain-containing protein \\
\hline GBI4972-PA & $x$ & & & & & $S$ & Thioredoxin reductase \\
\hline GBI5855-PA & $x$ & & & & & & Thioredoxin-2 \\
\hline GBI8955-PA & & $x$ & $x$ & $x$ & & $S$ & Phospholipid hydroperoxide glutathione peroxidase \\
\hline GBI9380-PA & & $\mathrm{x}$ & $x$ & & & & Thioredoxin peroxidase I \\
\hline GB30268-PA & $\mathrm{x}$ & $\mathrm{x}$ & $\mathrm{x}$ & & & & Glutathione s transferase SI \\
\hline GBI2586-PA & & & $\mathrm{x}$ & & & $\mathrm{S}$ & Protein disulfide-isomerase precursor \\
\hline GBI2447-PA & $x$ & & & & & & CAP, adenylate cyclase-associated protein I \\
\hline GBI3596-PA & & & $x$ & & & & ATP synthase \\
\hline GBI479I-PA & & & $x$ & & & & ATP synthase subunit \\
\hline GBI529I-PA & & & $x$ & & & & ATP synthase gamma subunit \\
\hline GBI6485-PA & & & $\mathrm{x}$ & & & & ATP synthase D chain \\
\hline GBI0989-PA & $\mathrm{x}$ & $\mathrm{x}$ & $\mathrm{x}$ & & & & Vacuolar ATPase catalytic subunit A \\
\hline GBII380-PA & $x$ & $x$ & $x$ & & & & Vacuolar $\mathrm{H}+$ ATPase $44 \mathrm{kDa} C$ subunit \\
\hline GBI2913-PA & $x$ & $x$ & $x$ & & & & Vacuolar proton pump E subunit \\
\hline GBI3499-PA & $x$ & $x$ & $x$ & & & & Vacuolar ATPase subunit G \\
\hline GBI5226-PA & $x$ & $x$ & & & & & Vacuolar ATPase subunit D I \\
\hline GBI7480-PA & $x$ & $x$ & $x$ & & & & Vacuolar ATPase subunit $\mathrm{H}$ \\
\hline GBI7499-PA & & & $x$ & & & & ADP/ATP translocase \\
\hline GBI9|7|-PA & $\mathrm{x}$ & $x$ & $\mathrm{x}$ & & & & Vacuolar ATPase $55 \mathrm{kDa}$ B subunit \\
\hline GB200I7-PA & $x$ & & & & & & Endoplasmic reticulum ATPase \\
\hline GBI0355-PA & & $x$ & $x$ & & & $S$ & Melittin \\
\hline GBI0695-PA & $x$ & $x$ & $x$ & & $x$ & & Pyruvate kinase \\
\hline GBI0992-PA & $x$ & & & & & & ATP citrate lyase isoform A \\
\hline GBII056-PA & $\mathrm{x}$ & $\mathrm{x}$ & $x$ & $x$ & & & Phosphoglycerate kinase isoform I \\
\hline GBII46I-PA & $x$ & & & & & & UTP-glucose-I-phosphate uridylyltransferase \\
\hline GBI 2488-PA & & & $x$ & & & & Aconitase \\
\hline GBI2573-PA & & $x$ & $x$ & $x$ & & & Citrate synthase \\
\hline GBI274I-PA & & & $x$ & & & & Aldehyde dehydrogenase \\
\hline GBI2949-PA & & $x$ & $x$ & & & & 6-Phosphogluconate dehydrogenase \\
\hline GBI3058-PA & & $x$ & & & $x$ & & Dihydroxyacetone kinase 2 \\
\hline GBI3237-PA & $x$ & $x$ & $x$ & & & & Phosphogluconate mutase \\
\hline
\end{tabular}


Table I (Continued)

\begin{tabular}{|c|c|c|c|c|c|c|c|}
\hline GBI3882-PA & $x$ & $x$ & & & & & L-lactate dehydrogenase \\
\hline GBI3955-PA & & $x$ & $x$ & & & & $\mathrm{~N}$-acetyltransferase 5 \\
\hline GBI45I7-PA & & $x$ & $x$ & & & & Isocitrate dehydrogenase \\
\hline GBI4798-PA & $x$ & $x$ & $x$ & & $x$ & & Glyceraldehyde-3-phosphate dehydrogenase 2 \\
\hline GBI4803-PA & & $x$ & $x$ & & & $\mathrm{~S}$ & Alpha,alpha-trehalase \\
\hline GBI5039-PA & $x$ & $x$ & $x$ & & & & Enolase \\
\hline GBI5052-PA & $x$ & $x$ & $x$ & & & & Phosphoglyceromutase \\
\hline GBI5463-PA & & $x$ & & & $x$ & & Aldolase \\
\hline GBI5543-PA & & $x$ & & $x$ & & & Malate/L-lactate dehydrogenases \\
\hline GBI5619-PA & $x$ & & & & & & Transketolase-like \\
\hline GBI5888-PA & & $x$ & $x$ & & & & Carbonic anhydrase \\
\hline GBI6429-PA & $x$ & $x$ & $x$ & $x$ & & & Glucose-6-phosphate isomerase \\
\hline GBI6464-PA & $x$ & $x$ & $x$ & & & & malate dehydrogenase \\
\hline GBI695I-PA & $x$ & & & & & & Malic enzyme \\
\hline GBI7II3-PA & $x$ & $x$ & $x$ & & & & Phosphofructokinase \\
\hline GBI7473-PA & $x$ & $x$ & $x$ & $x$ & & & Triosephosphate isomerase I \\
\hline GBI8I09-PA & & $x$ & & & $x$ & & Aldose reductase (NADP+) \\
\hline GBI8727-PA & $x$ & $x$ & $x$ & & & & Malate dehydrogenase \\
\hline GBI9030-PA & $x$ & $x$ & $x$ & & & & Aldo/keto reductase family protein \\
\hline GBI9387-PA & & $x$ & $x$ & & $x$ & & Hexokinase $A$, isoform $A$ \\
\hline GBI9460-PA & $x$ & $x$ & $x$ & & & & Aldolase, isoform F \\
\hline GBII665-PA & & $x$ & $x$ & $\mathrm{X}$ & & $\mathrm{S}$ & Chitinase-like protein \\
\hline GBII876-PA & & & $x$ & & & $\mathrm{~S}$ & LDLa domain containing chitin binding protein \\
\hline GBI6986-PA & & $x$ & $x$ & & & $\mathrm{~S}$ & Endochitinase precursor \\
\hline GBI0397-PA & & & $x$ & & & & Alpha-crystallin \\
\hline GBI0800-PA & $x$ & & & & & & T-complex protein I \\
\hline GBI0836-PA & $x$ & & & & & & HSP70 \\
\hline GBI4758-PA & $\mathrm{x}$ & $x$ & $x$ & $x$ & & & Heat shock protein 90 \\
\hline GBI4852-PA & $\mathrm{x}$ & $x$ & $x$ & $\mathrm{X}$ & & & Heat shock protein 8 isoform I \\
\hline GBI50I6-PA & $x$ & $x$ & $x$ & & & & Heat shock protein cognate 3 \\
\hline GBI7056-PA & $x$ & $x$ & $x$ & & & & Cyclophilin I \\
\hline GBI8662-PA & & & $x$ & & & & Alpha-crystallin, small HSP \\
\hline GBI8969-PA & $\mathrm{x}$ & & $x$ & & & & Heat shock protein 60 \\
\hline GBI28I8-PA & & & $x$ & & & & Histone $2 \mathrm{~A}$ \\
\hline GBI4548-PA & & $x$ & $x$ & & & $S$ & Deoxyribonuclease II \\
\hline GBI65I5-PA & $\mathrm{x}$ & & & & & & ATP dependent DNA helicase \\
\hline GBI9247-PA & $\mathrm{x}$ & & & & & & Elongation factor 2, isoform I \\
\hline GBI6568-PA & & & $x$ & $\mathrm{X}$ & & & Cytochrome c oxidase subunit \\
\hline GBI9293-PA & $x$ & $x$ & $x$ & & & & Cytochrome c \\
\hline GBI9729-PA & $x$ & $x$ & & & & $\mathrm{~S}$ & Cytochrome c \\
\hline GBII059-PA & $\mathrm{x}$ & & & & & & Retinoid- and fatty-acid binding protein \\
\hline GBI5044-PA & & $x$ & $x$ & $\mathrm{x}$ & & & Phosphatidylethanolamine-binding protein \\
\hline GBI4639-PA & & $x$ & $x$ & & & $\mathrm{~S}$ & Major royal jelly protein 8 \\
\hline GBI6324-PA & & $x$ & $x$ & & & $\mathrm{~S}$ & Major royal jelly protein 9 \\
\hline GBI295I-PC & $x$ & $x$ & $x$ & & & & 14-3-3-like protein \\
\hline
\end{tabular}


Table I (Continued)

\begin{tabular}{|c|c|c|c|c|c|c|c|}
\hline GBI5202-PA & & $\mathrm{x}$ & & & & & DJ-I, neuroprotective transcriptional co-activator \\
\hline GBI5582-PA & & $x$ & $\mathrm{X}$ & & & & 14-3-3 epsilon \\
\hline GBI6I78-PA & $\mathrm{X}$ & & & & & & Neuropeptide Y receptor \\
\hline GBI67I6-PA & & & $\mathrm{X}$ & & & $S$ & Leucine-rich repeat-containing protein \\
\hline GBI6072-PA & $\mathrm{x}$ & $x$ & $\mathrm{X}$ & & & & Iron regulatory protein IB \\
\hline GBI0536-PA & & & $\mathrm{X}$ & & & & Odorant binding protein 14 \\
\hline GBI9662-PA & & $x$ & & & & $S$ & Juvenile hormone binding protein \\
\hline GBI9745-PA & & $\mathrm{x}$ & & & & $\mathrm{S}$ & Transferrin \\
\hline GBI0009-PA & $\mathrm{X}$ & $x$ & $\mathrm{X}$ & & $x$ & & Tubulin alpha-I chain \\
\hline GBI009I-PA & & & $\mathrm{X}$ & & & $\mathrm{S}$ & Cuticlin-I precursor \\
\hline GBI0I22-PA & & $x$ & $\mathrm{X}$ & & $x$ & & Tubulin, beta, 2 \\
\hline GBI0275-PA & $\mathrm{X}$ & $x$ & $\mathrm{X}$ & $x$ & & & Tubulin isoform B \\
\hline GBI05I4-PA & $\mathrm{X}$ & $x$ & $x$ & & $x$ & & alpha tubulin \\
\hline GB I I 282-PA & $\mathrm{X}$ & $x$ & $\mathrm{X}$ & & & & Moesin isoform D \\
\hline GBII920-PA & $\mathrm{X}$ & & & & & & Tubulin \\
\hline GBI26I4-PA & & $x$ & & & & & Actin \\
\hline GBI3049-PA & & $x$ & & & & & Tubulin, beta, 2 \\
\hline GBI3229-PA & $x$ & & & & & & PDZ and LIM domain protein \\
\hline GBI3999-PA & $x$ & $x$ & $x$ & & & $\mathrm{~S}$ & Vitellogenin \\
\hline GBI5794-PA & & & $x$ & & & $S$ & Cuticlin-I precursor \\
\hline GBI6448-PA & & $x$ & $x$ & $\mathrm{X}$ & & & Annexin IX \\
\hline GBI7673-PA & $\mathrm{X}$ & & & & & & Talin-I \\
\hline GBI768I-PA & $\mathrm{X}$ & $x$ & $\mathrm{X}$ & $\mathrm{X}$ & & & Actin-5C isoform I \\
\hline GBI89I7-PA & & $x$ & $\mathrm{X}$ & & & & Cofilin/actin-depolymerizing factor homolog \\
\hline GBI2II3-PA & & & $x$ & & & & Porin \\
\hline GBI40I2-PA & & & $\mathrm{X}$ & & & & Phosphate carrier \\
\hline GBI6577-PA & & & $\mathrm{X}$ & & & & Sialin, inorganic phosphate cotransporter \\
\hline GBI I 987-PA & & $\mathrm{x}$ & & $\mathrm{X}$ & & & Unknown \\
\hline GBI 2562-PA & $\mathrm{X}$ & $x$ & $\mathrm{X}$ & & & & Hypothetical protein \\
\hline GBI3778-PA & $\mathrm{X}$ & & & & & $S$ & Unknown \\
\hline GBI4970-PA & $\mathrm{X}$ & & & & & & Muscle-specific protein 300 \\
\hline GBI5662-PA & $\mathrm{X}$ & $x$ & $\mathrm{X}$ & $\mathrm{X}$ & & & Unknown \\
\hline GBI73II-PA & & $x$ & $\mathrm{X}$ & $\mathrm{X}$ & & $\mathrm{S}$ & Unknown \\
\hline GBI7500-PA & & & $\mathrm{X}$ & & & $\mathrm{S}$ & Hypothetical protein \\
\hline GBI9255-PA & $\mathrm{X}$ & & & & & $\mathrm{S}$ & Osiris I4 CGII55-PA \\
\hline GB30569-PA & & $x$ & $x$ & & & $S$ & Hypothetical protein \\
\hline
\end{tabular}

Proteins were identified by MS/MS analysis of one-dimensional gel and gel-free analysis of tryptic peptides from spermathecal fluid extracted from mated and virgin queens. Data are compared to the previous reported analysis of the male seminal fluid and sperm proteomes [19]. Details of the mass spectrometry analysis and detailed matching are shown in Additional data file I. Significant identification of peptides from a specific bee locus number are shown with an 'X' for gel analyses; the number of proteins predicted to be secreted (Pred. secret.) are shown with an 'S' based on consensus of analysis of amino acid sequences using two different software packages TargetP [52] and IPsort [53]. 
Table 2

\begin{tabular}{|c|c|c|c|c|}
\hline PreRelease 2 accession & RefSeq GI & Bee gene ID & Functional group & Dm match \\
\hline GBI0467-PA & 110755553 & 412675 & AA metabolism & CG4233 \\
\hline GBI0973-PA & 58585146 & 550932 & AA metabolism & CG32031 \\
\hline GBI5049-PA & 66500225 & 412948 & AA metabolism & CG7470 \\
\hline GBI5I7I-PA & 110763628 & 410582 & AA metabolism & CG8782 \\
\hline GBI6218-PA & 66559229 & 411808 & AA metabolism & CGI4I7 \\
\hline GBI764I-PA & 66563168 & 409196 & AA metabolism & CGI640 \\
\hline GBI8844-PA & 110775909 & 726943 & AA metabolism & CG8430 \\
\hline GBI0I33-PA & 66513527 & 409398 & AntiOx & CGII793 \\
\hline GBI0498-PA & 66535082 & 551975 & AntiOx & CGII765 \\
\hline GBI 2029-PA & 66517659 & 552722 & AntiOx & CGI532 \\
\hline GBI4972-PA & 48140590 & 410032 & AntiOx & CG2I5I \\
\hline GBI5855-PA & 48104680 & 409451 & AntiOx & CG3I884 \\
\hline GBI8955-PA & 110756698 & 726269 & AntiOx & CGI2013 \\
\hline GBI9380-PA & 66548188 & 409954 & AntiOx & CGI633 \\
\hline GB30268-PA & 66534655 & & AntiOx & CG8938 \\
\hline GBI 2586-PA & $6653185 \mid$ & 551435 & AntiOx/Chaperone & CG6988 \\
\hline GBI 2447-PA & 110766149 & 410158 & ATP related & CG506I \\
\hline GBI3596-PA & 110762902 & 551766 & ATP synthesis & CGIIIS4 \\
\hline GBI479I-PA & 48100966 & 409114 & ATP synthesis & CG3612 \\
\hline GBI529I-PA & $66554 \mid 56$ & 552699 & ATP synthesis & CG7610 \\
\hline GBI6485-PA & 48098315 & 410557 & ATP synthesis & CG6030 \\
\hline GBI0989-PA & 66515272 & 551093 & ATP/transport & CG3762 \\
\hline GBII $380-P A$ & 110756584 & 411892 & ATP/transport & CG8048 \\
\hline GBI29|3-PA & 66556287 & 552720 & ATP/transport & CGI088 \\
\hline GBI3499-PA & 66553147 & 551961 & ATP/transport & CG6213 \\
\hline GBI5226-PA & 66515294 & 411295 & ATP/transport & CG8I86 \\
\hline GBI7480-PA & - & 409055 & ATP/transport & CGI7332 \\
\hline GBI7499-PA & 58531215 & 406075 & ATP/transport & CGI6944 \\
\hline GBI917I-PA & 66531434 & $55|72|$ & ATP/transport & CGI7369 \\
\hline GB200I7-PA & 66534286 & 409377 & ATP/transport & CG233I \\
\hline GBI0355-PA & 58585154 & 406130 & Bee venom & - \\
\hline GBI0695-PA & 66548684 & 552007 & $\mathrm{C}$ metabolism & CG7070 \\
\hline GBI0992-PA & 66530142 & 550686 & C metabolism & CG8322 \\
\hline GBII056-PA & 110763826 & 411576 & C metabolism & CG3 I 27 \\
\hline GBII46I-PA & 66536233 & 412069 & $\mathrm{C}$ metabolism & CG4347 \\
\hline GBI 2488-PA & 48098039 & 408446 & $\mathrm{C}$ metabolism & CG9244 \\
\hline GBI 2573-PA & 66521738 & 410059 & $\mathrm{C}$ metabolism & CG386I \\
\hline GBI274I-PA & 66530423 & 550687 & C metabolism & CG3752 \\
\hline GBI2949-PA & 66547531 & 552712 & C metabolism & CG3724 \\
\hline GBI3058-PA & 110763782 & 413697 & $\mathrm{C}$ metabolism & - \\
\hline GBI3237-PA & 66561330 & 411897 & $\mathrm{C}$ metabolism & CG5I65 \\
\hline
\end{tabular}


Table 2 (Continued)

\begin{tabular}{|c|c|c|c|c|}
\hline GBI3882-PA & 110758428 & 411188 & $\mathrm{C}$ metabolism & CGI0160 \\
\hline GBI3955-PA & 66517612 & $4 \mid 4027$ & C metabolism & CGI4222 \\
\hline GBI45I7-PA & 110764717 & 551276 & C metabolism & CG7I76 \\
\hline GBI4798-PA & 48142692 & 410122 & C metabolism & CGI 2055 \\
\hline GBI 4803-PA & 66524360 & 410484 & C metabolism & CG9364 \\
\hline GBI5039-PA & 110761968 & 552678 & C metabolism & CGI7654 \\
\hline GBI5052-PA & 66550890 & 552736 & $\mathrm{C}$ metabolism & CGI72I \\
\hline GBI5463-PA & 110748959 & 725455 & $\mathrm{C}$ metabolism & CG6058 \\
\hline GBI5543-PA & 66523770 & 410520 & C metabolism & CGI05I2 \\
\hline GBI5619-PA & 110751363 & 550804 & $\mathrm{C}$ metabolism & CG8036 \\
\hline GBI 5888-PA & 48095863 & 408827 & C metabolism & CG7820 \\
\hline GBI6429-PA & 66499293 & 551154 & C metabolism & CG825I \\
\hline GBI6464-PA & 66513092 & 408950 & C metabolism & CG7998 \\
\hline GBI695I-PA & $11076156 \mid$ & 411813 & C metabolism & CG 10120 \\
\hline GBI7II3-PA & - & 724724 & C metabolism & CG400I \\
\hline GBI7473-PA & 148224276 & 726117 & C metabolism & CG2I7I \\
\hline GBI8I09-PA & 66525576 & 551968 & C metabolism & CG6084 \\
\hline GBI8727-PA & 66506786 & 411014 & $\mathrm{C}$ metabolism & CG5362 \\
\hline GBI9030-PA & 110763386 & 552018 & C metabolism & CGI0638 \\
\hline GBI9387-PA & 66525954 & 551005 & C metabolism & CG300I \\
\hline GBI9460-PA & 110748949 & 550785 & $\mathrm{C}$ metabolism & CG6058 \\
\hline GBII665-PA & $665|46| 4$ & 413324 & Cell wall degradation, antifungal & CGI780 \\
\hline GBII876-PA & 110760993 & 551323 & Cell wall degradation, antifungal & CG8756 \\
\hline GBI6986-PA & 66511507 & 551600 & Cell wall degradation, antifungal & CG9307 \\
\hline GBI0397-PA & 110750754 & 724274 & Chaperone & CG4533 \\
\hline GBI0800-PA & 66563290 & 409296 & Chaperone & CG8977 \\
\hline GBI0836-PA & 66505007 & 408706 & Chaperone & CG6603 \\
\hline GBI4758-PA & 110758212 & 408928 & Chaperone & CGI242 \\
\hline GBI 4852-PA & 66537940 & 409418 & Chaperone & CG4264 \\
\hline GBI50I6-PA & II 0754998 & 409587 & Chaperone & CG4|47 \\
\hline GBI7056-PA & 66534750 & 409890 & Chaperone & CG9916 \\
\hline GBI8662-PA & II 0750756 & 410087 & Chaperone & CG4533 \\
\hline GBI8969-PA & 66547450 & 409384 & Chaperone & CGI2I0I \\
\hline GBI28I8-PA & 110749634 & 725450 & DNA/RNA & CG31618 \\
\hline GBI4548-PA & 48138800 & 413489 & DNA/RNA & CG7780 \\
\hline GBI65I5-PA & 110768389 & 412756 & DNA/RNA & CG31916 \\
\hline GBI9247-PA & 66508439 & 409167 & DNA/RNA & CG2238 \\
\hline GBI6568-PA & 66534766 & 552610 & Electron transport & CGII0I5 \\
\hline GB19293-PA & 48096996 & 408270 & Electron transport & CGI7903 \\
\hline GBI9729-PA & 110760474 & 724543 & Electron transport & CGI7903 \\
\hline GBII059-PA & II 0758758 & 408961 & Lipid metabolism & CGII064 \\
\hline GBI5044-PA & 66524882 & 408516 & Lipid metabolism & CG6I80 \\
\hline GBI4639-PA & 58585070 & 406067 & Royal Jelly & CGI629 \\
\hline
\end{tabular}


Table 2 (Continued)

\begin{tabular}{|c|c|c|c|c|}
\hline GBI6324-PA & 67010041 & 409873 & Royal Jelly & CGI629 \\
\hline GBI295I-PC & 48097086 & 408289 & Signalling & CGI7870 \\
\hline GBI5202-PA & 66531474 & 551882 & Signalling & CGI349 \\
\hline GBI5582-PA & 48096523 & 408951 & Signalling & CG31196 \\
\hline GBI6I78-PA & 66520994 & $4|321|$ & Signalling & CG58II \\
\hline GBI67I6-PA & 110748765 & $72504 I$ & Signalling & CG856I \\
\hline GBI6072-PA & 66550870 & 409485 & Signalling/AntiOx & CG6342 \\
\hline GBI0536-PA & 94158822 & & Small molecular binding protein & - \\
\hline GBI9662-PA & 110766389 & 727028 & Small molecular binding protein & CG2016 \\
\hline GBI9745-PA & 58585086 & 406078 & Small molecular binding protein & CG6186 \\
\hline GBI0009-PA & 66524874 & 412886 & Structural & CGI913 \\
\hline GBI009I-PA & 48132776 & 413256 & Structural & CG7802 \\
\hline GBI0I22-PA & 110762983 & 410559 & Structural & CG9277 \\
\hline GBI0275-PA & 48095525 & 408782 & Structural & CG9277 \\
\hline GBI05I4-PA & 66521545 & 408388 & Structural & CGI913 \\
\hline GBI I 282-PA & 66512737 & 412799 & Structural & CGI07I \\
\hline GBII920-PA & 48095543 & 410994 & Structural & CG340I \\
\hline GBI26I4-PA & 66509769 & 410075 & Structural & CGI8290 \\
\hline GBI3049-PA & 48095547 & 410996 & Structural & CG9277 \\
\hline GBI3229-PA & 110760290 & 410204 & Structural & CG30084 \\
\hline GBI3999-PA & 58585104 & 406088 & Structural & CG3II50 \\
\hline GBI5794-PA & 66546405 & 410975 & Structural & CG7802 \\
\hline GBI6448-PA & 110766532 & 409533 & Structural & CG5730 \\
\hline GBI7673-PA & 110762380 & 408396 & Structural & CG683I \\
\hline GBI768I-PA & 48137684 & 406122 & Structural & CG4027 \\
\hline GBI89|7-PA & 110751158 & 725718 & Structural & CG4254 \\
\hline GBI2II3-PA & 66521459 & 551325 & Transport & CG6647 \\
\hline $\mathrm{GB}|40| 2-\mathrm{PA}$ & 66525867 & 413517 & Transport & CG9090 \\
\hline GBI6577-PA & 110755759 & 411052 & Transport & CG3036 \\
\hline GBII 987-PA & 110764400 & $72664 \mid$ & Unknown & - \\
\hline GBI 2562-PA & 66522463 & 408421 & Unknown & CGI05I3 \\
\hline GBI3778-PA & 110755198 & 551170 & Unknown & CG33196 \\
\hline GBI4970-PA & II 0749723 & 409731 & Unknown & CGI825I \\
\hline GBI5662-PA & 110749015 & 724721 & Unknown & CG 10962 \\
\hline GBI73II-PA & 110766503 & 552228 & Unknown & CG8444 \\
\hline GBI7500-PA & 110755329 & 725960 & Unknown & - \\
\hline GBI9255-PA & 48098542 & 408538 & Unknown & CGII55 \\
\hline GB30569-PA & AmeLG8_WGA346_4 [LG8] & & Unknown & - \\
\hline
\end{tabular}

Details of the PreRelease 2 accession numbers, the NCBI RefSeq GI numbers and the Bee Gene ID numbers are provided in the first three columns. Functional groups and corresponding genes in Drosophila (Additional data file 4) are provided in separate columns for each protein identified in the spermathecal fluid of the honeybee. 


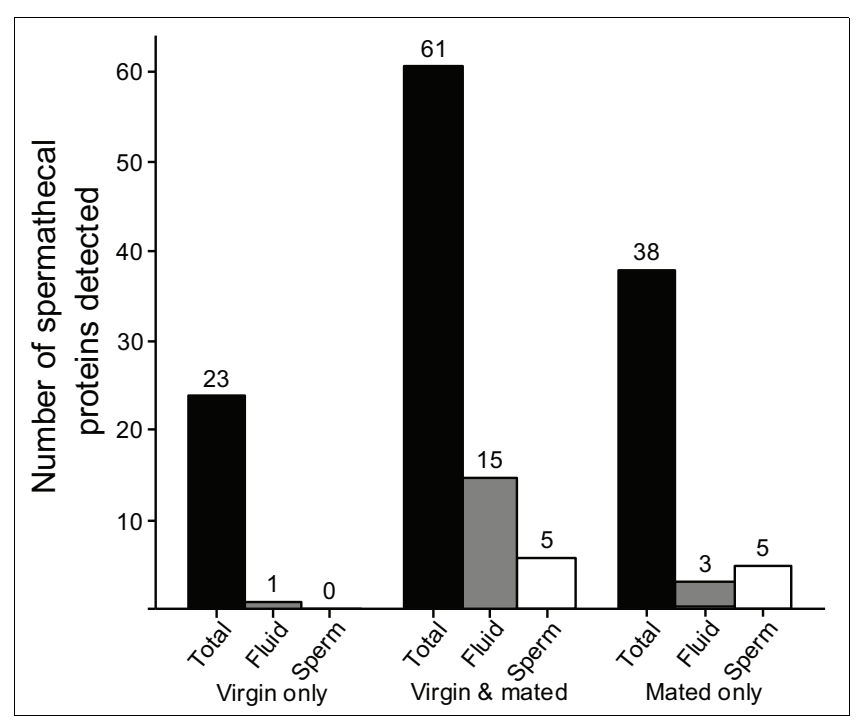

Figure 3

Spermathecal fluid proteins in virgin and mated queens. A graphical comparison of the spermathecal proteins detected in our study. The black bars show the total number of proteins that were detected in both virgin and mated queens as well as the number of proteins detected in virgins or mated queens only. The number of spermathecal proteins that were also found in seminal fluid and sperm are shown by grey and white bars, respectively. Half of the spermathecal proteins (50\%) were found in mated as well as virgin queens, although subsets of proteins were unique for mated $(30 \%)$ and virgin queens $(20 \%)$. Overlaps of spermathecal proteins with those reported for sperm and seminal fluid [19] were generally low and are shown by the grey and white bars, respectively.

it is unlikely that these are contaminating sperm proteins but instead represent the expression of the same gene that queens secrete into the spermathecal fluid. Only 5 (4\%) proteins were found in sperm samples in our previous publication from male ejaculates and also in the spermathecal fluid list from mated queens presented here (Figure 3). Comparison of the spermathecal list with the top 12 most abundant hemolymph proteins we have previously detected by mass spectrometry [19] also revealed no overlap. We have also compared the protein profiles of spermathecal fluid identified here and our previous analysis of seminal fluid [19] and again found substantial differences. Only 19 (16\%) out of the set of 122 spermathecal proteins were also detected in this previously reported seminal fluid proteome. Sixteen of this set of 19 proteins were also present in the spermathecal fluid of virgin queens and, thus, cannot be considered as contaminants from male seminal fluid (Table 1; Additional data file 1). This provides evidence that while qualitative assessment of seminal fluid contamination in our spermathecal fluid samples was minimal at the depth of the analysis performed, some identical proteins are present, which appear to be expressed and secreted by both males into their ejaculate and by females into the spermatheca. Our dataset of 122 proteins also allowed a comparison of the spermathecal protein population of virgin and mated queens. We detected peptides for 61 proteins present in both virgin and mated queens (Figure 3), but each group also had unique sets of proteins not found in the other. We found that 38 (30\%) spermathecal fluid proteins were only detected in mated queens and 23 (19\%) proteins were only detected in virgin queens. Obviously, protein profiles differ between young, virgin and old inseminated queens, but our study was not able to distinguish whether this proteomic changes are caused by queen age or mating status. Future work will be needed to resolve this issue; however, aged virgin females are physiologically and technically extremely difficult to obtain to test this issue.

Spectral counts in our LC-MS/MS data from spermathecal fluid revealed that counts for particular proteins were sometimes substantially different between mated and virgin queens (Additional data file 2). This indicates that the protein concentrations might substantially differ between spermathecal fluid of mated and virgin queens. Future work is obviously needed to quantify the proteins with different spectral counts. To do this, biological replicates of spectral counts based on LC-MS/MS will be necessary, but were beyond the scope of the current study.

To further explore the metabolic network established in the spermathecal fluid, we created metabolic networks of spermathecal fluid and seminal fluid using data from the Kyoto Encyclopedia of Genes and Genomes (KEGG) [36,37] associated with our identified proteins. This was then visualized with the Cytoscape software package [38]. The resulting networks are presented in Figure 4 (see also an annotated version provided as Additional data file 3), where colored nodes (rounded squares) represent enzymes in different functional categories, metabolites are shown as small grey circles, while the reaction is shown as connecting lines between the enzymes and metabolite nodes. The two networks differ in their degree of connectivity and the number of hubs that join multiple reactions. In the seminal fluid network there are discrete metabolic reactions leading to six clusters of reactions plus the redox reaction of disulfide isomerase. This is consistent with sperm needing only to survive for a short period in seminal fluid and the substrates necessary for these reactions being pre-charged in seminal fluid prior to ejaculation. In contrast, the spermathecal fluid is a well-connected single metabolic entity. It contains 5 of the 14 enzyme nodes present in the seminal fluid, but also an extra 23 enzyme nodes that combine the 6 clusters in the seminal fluid into a single metabolic network. Obviously, the different metabolic steps are interlinked with many products representing the substrates for other reactions. This correlates with the requirement of spermathecal fluid to maintain homeostatic functions for years, perhaps with only a small set of entry metabolites. The terminal metabolite nodes of the network are potential substrates to be transported in or out of the spermatheca, across the spermathecal wall.

The spermathecal network shows the key features of biochemistry needed for sperm protection and maintenance. It 
shows a near complete glycolytic pathway that is absent from the seminal fluid and a large series of components for a vacuolar like protein pumping ATPase. It also contains a variety of antioxidant defenses, most shared with seminal fluid proteins, although it is often different gene products that catalyze the same reactions. These three networks interact through common ATP/ADP and NAD(P)/NAD(P)H pools (Additional data file 3).

Protons $\left(\mathrm{H}^{+}\right)$are presented as metabolites here and are heavily connected nodes (Additional data file 3); we kept these in the network given that metabolic maintenance of $\mathrm{pH}$ may be an important function in spermathecal fluid [39]. However, removal of this 'currency metabolite' [40] does not significantly break the highly interconnected structure of the spermathecal fluid network, but it does further fragment the seminal fluid network (data not shown).

\section{Discussion}

The first large-scale identification of proteins that are present in the spermathecal fluid of honeybee queens is an essential step in uncovering the molecular regulation of long-term sperm storage. A comparison of identified protein lists between our spermathecal fluid samples and those from sperm and hemolymph revealed surprisingly little overlap. Our analysis of spermathecal fluid of virgin queens, which could not have been contaminated with sperm proteins, allowed us to further decrease the number of possible sperm contaminants to only five proteins that we subsequently removed from our final list to avoid any form of contamination from stored sperm. The detection of these remaining sperm proteins in spermathecal fluid does not necessarily result from contamination, as proteins might be expressed in both locations in vivo. Information about the proteineous contributions of females towards stored sperm is still very limited. An expressed sequence tag analysis in Drosophila

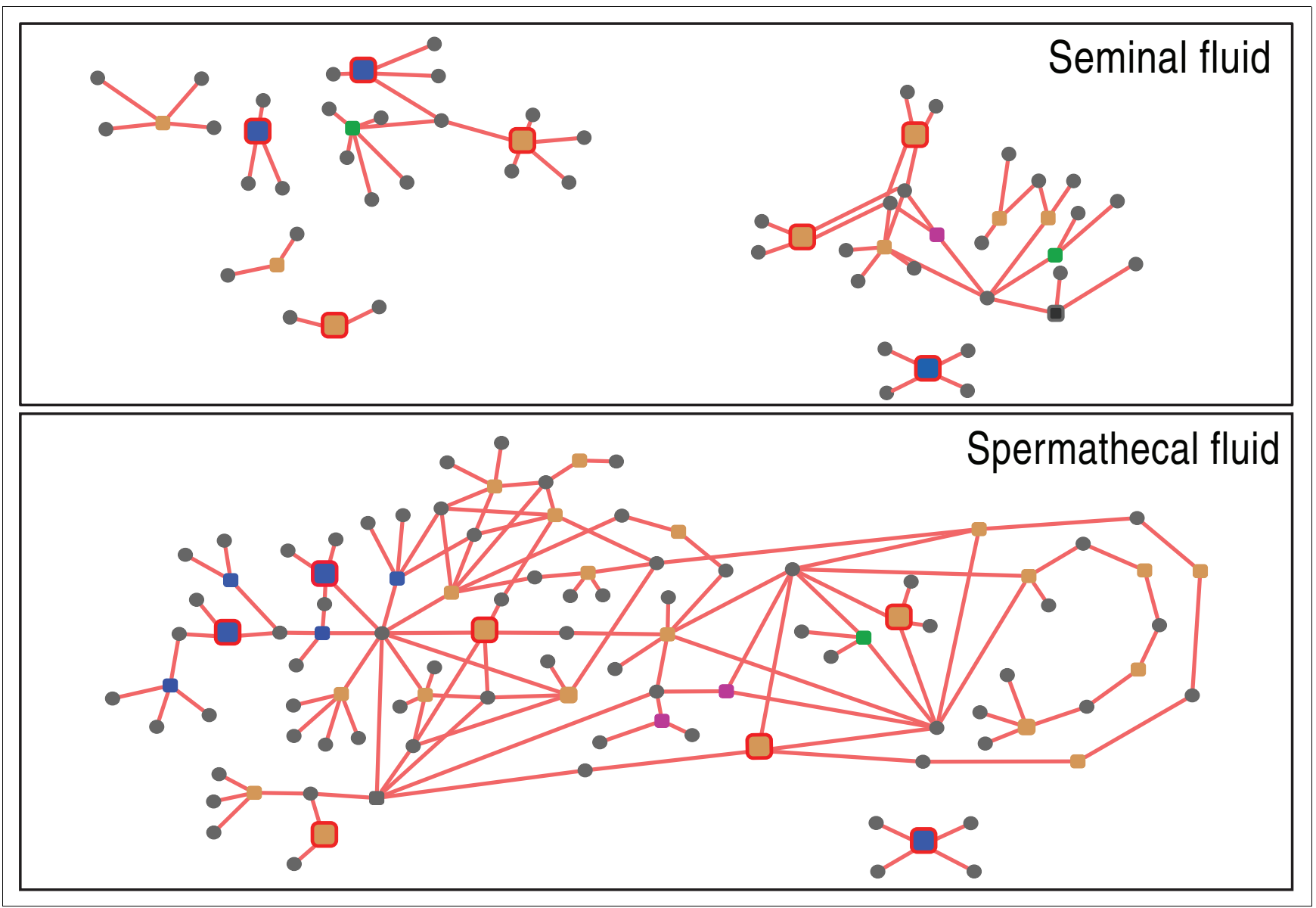

Figure 4

Metabolic networks of seminal and spermatecal fluid. Visualization of spermathecal and seminal fluid metabolic networks based on the proteins identified in this study and Baer et al. [19]. Colored nodes (rounded squares) represent enzymes in different functional categories, metabolites are shown as small grey circles, and reactions are shown as connecting lines between the enzyme and metabolite nodes. Additional data file 3 provides Enzyme Commission (EC) numbers and metabolite names for all features that are noted. The seven enzymes in common between the two datasets are highlighted by increased size, and red outlines indicate nodes with a consistent spatial arrangement in both networks. 
detected 42 transcripts that are enriched for expression in the spermatheca [41] but we noted that only 3 proteins within the honeybee spermathecal proteome list had significant sequence similarity to proteins predicted from these Drosophila transcripts. A set of 19 genes highly expressed in spermathecae were identified during analysis of the Hr39 gene in Drosophila, which is reported to regulate Drosophila female reproductive tract development and function [42]. While there are orthologs for most of these proteins in Apis, only one of the Drosophila genes highly expressed in spermathecae (Hsc7O-4) has orthologs in our protein set. These orthologs are among the heat shock protein molecular chaperones (Table 2). Recently released microarray analysis of virgin and mated spermatheca from Drosophila [43,44] reveals a large number of spermatheca enriched transcripts. Sequence comparison with the Apis spermathecal proteins in Table 2 reveal that approximately $47 \%$ of the corresponding genes in Drosophila have significant spermatheca-enriched expression patterns, while a further $30 \%$ have significantly spermatheca-depleted expression patterns (Additional data file 4).

The spermathecal fluid proteins of the honeybee differ substantially from those we have reported in seminal fluid [19], supporting the idea that selection on seminal and spermathecal fluid were substantially different. Seminal fluid was selected to increase insemination and paternity success whereas spermathecal fluid evolved to maximize sperm survival. Nevertheless, we were surprised by the finding of a small 20\% overlap between these two protein sets (Figure 2 and Table 1) given that seminal fluid and spermathecal fluid are expected to also share common roles, such as keeping sperm alive, reducing oxidative stress, nourishing sperm or protecting sperm from microbial attacks. The network analysis shows that while different proteins are involved, many biochemical classes and enzymatic functions are the same in both fluids. Indeed, previous research in ants [6] and honeybees [7] shows that both spermathecal fluid and seminal fluid keep sperm viable, but we here show that the specific proteins to achieve this differ substantially between the male and female. Sperm is obviously able to survive in both of these 'habitats' but it might have to undergo developmental changes at the beginning of its storage to achieve this. Our finding that spermathecal fluid of virgins, which are anticipating freshly ejaculated sperm to arrive in the spermatheca, differs, in part, from that in mated queens (Figure 3), where sperm has been stored for several months, supports this idea. Consequently, the sperm storage process might be more complicated than assumed so far, and may involve a period of adjustment when the female partially mimics the seminal fluid environment but then modifies the conditions. This may minimize the energetic costs of sperm storage over time or select for specific sperm traits and thereby manipulates the paternity success of her mates.
Some of the components of the spermathecal fluid are likely linked to the need for protection of the sperm from damaging infections or damaging chemical substances that might be detrimental to long term storage. For example, several chitinases were found that might be used in defense for degrading fungal cell walls [RefSeq Gi 66514614, 110760993, 66511507]. We also found an elaborate antioxidant defense system of nine different enzymes, including defenses against superoxide, hydrogen peroxide and lipid peroxides, that likely help prevent oxidative damage to sperm during their substantial hiatus. This is consistent with the evidence of a high activity of several antioxidant defense enzymes in spermathecal fluid [8]. Also, we found a number of chelating proteins, several with roles in $\mathrm{Fe}^{2+}$ binding, which again may represent an antioxidant defense by preventing metal-catalyzed reactive oxygen species production and/or a scavenging of metals to prevent their use in the growth and proliferation of bacterial or fungal infections.

The most prominent aspect of the spermathecal metabolic network is glycolytic metabolism, which is a pathway for fructose degradation to organic acids and the production of both NADH and ATP (Figure 4). NADH will be needed to fuel the antioxidant enzymes noted above. ATP from this extracellular glycolysis could be used to fuel the vacuolar-like ATPase (Table 1). In many animal cell types, such an ATPase normally hydrolyzes cellular ATP and is used to pump protons out of cells, leading to raising of cellular $\mathrm{pH}$ and activation of $\mathrm{K}^{+}$ influx channels that replace the expelled $\mathrm{H}^{+}$with $\mathrm{K}^{+}[45,46]$. The long established basic $\mathrm{pH}$ and high $\mathrm{K}^{+}$concentration in the spermatheca that has been hypothesized to slow sperm metabolic rate $[47,48]$ could be catalyzed by such an ATPase pump activity. However, to our knowledge, such pumps have not been reported to operate in the direction required here, raising extracellular $\mathrm{pH}$, so the link between vacuolar-like ATPases and the spermathecal $\mathrm{pH}$ and $\mathrm{K}^{+}$concentrations requires more research.

An intriguing possibility is that this glycolytic pathway is also feeding carbon substrates to the sperm to maintain their own internal metabolism. Fructose as a carbon source seems to be of specific importance for honeybees [49] and the dominance of gycolytic pathway proteins in male reproductive organs has been reported earlier [20]. Klenk et al. [5] previously identified the glycolytic enzyme triosephosphate isomerase as a mating enhanced component of the honeybee spermathecal fluid. Together, our evidence is significant for an extracellular glycolytic pathway operating in the spermathecal fluid. This could suggest a change in primary carbon substrate for sperm, because in seminal fluid they are fueled by their own internal energy stores. This switch in substrates may be critical in establishing a new, slower metabolic rate required for long-term homeostasis in the spermatheca. 


\section{Conclusions}

Our large-scale identification of proteins within the spermathecal fluid of honeybee queens offers an intriguing insight into the details of female sperm storage. Our data indicate that females provide stored sperm with a complex mixture of proteins that form a metabolically connected network. They also suggest that some essential physiological requirements of sperm have effectively been 'outsourced' and are now provided by the female. In this respect, sperm storage could be regarded as a specialized from of endosymbiosis between males and females, post-copulation but pre-fertilization.

\section{Materials and methods Sample preparation}

Spermathecal fluid was collected by dissecting virgin and mated queens using a Leica stereo microscope at $40 \times$ to $62 \times$ magnification. All dissections were performed with fine watchmaker forceps (INOX 5 , Biology) and in Hayes solution (9.0 g/l NaCl, $0.2 \mathrm{~g} / \mathrm{l} \mathrm{CaCl}_{2}$, $0.2 \mathrm{~g} / \mathrm{l} \mathrm{KCl}, 0.1 \mathrm{~g} / \mathrm{l} \mathrm{NaHCO}_{3}, \mathrm{pH}$ 8.7). Spermathecal fluid was sampled from a total of 206 mated and 64 virgin queens. Mated queens were egg laying mother queens at least 9 months of age and were provided by several local beekeepers. Virgin queens were obtained by grafting and used at an average age of 6 days, being the age when queens typically perform their nuptial flights. To sample spermathecal fluid, queens were briefly anesthetized in $\mathrm{CO}_{2}$ for 20 to 30 seconds after which their spermathecae were immediately dissected and transferred to a drop of Hayes solution. The dense tracheal network surrounding the spermatheca was carefully removed. The spermatheca was then washed in a second drop of Hayes to minimize contamination by hemolymph. The spermatheca was then placed on a microscopic slide. After the removal of remaining Hayes an injection needle was used to pierce a small whole into the spermathecal wall. The spermathecal fluid was then collected out of the lumen using a fine glass capillary. For each biological sample we pooled samples from 20 to 30 queens. For the samples from mated queens spermathecal fluid was separated from the surrounding stored sperm by centrifugation for 25 minutes at $850 \times \mathrm{g}$ at $4^{\circ} \mathrm{C}$. The supernatant (spermathecal fluid) was collected and centrifuged again at 18,620 $\times \mathrm{g}$ for 10 minutes at $4^{\circ} \mathrm{C}$ to remove remaining sperm. Samples from virgin queens were briefly centrifuged at $10,000 \times \mathrm{g}$ but not processed any further and all spermathecal fluid samples were frozen at $-80^{\circ} \mathrm{C}$ prior to further analyses. To collect secretions of the spermathecal glands, we collected up to 20 glands for each biological sample and kept them in $50 \mu \mathrm{l}$ of Hayes on ice. The glands were then carefully opened at their distal end using watchmaker forceps to allow the gland content to dissolve into the surrounding solution. Separation of the gland tissue from the dissolved gland secretions was done by centrifugation for 20 minutes at $850 \times \mathrm{g}$ and at $4^{\circ} \mathrm{C}$.

\section{Protein profiling using gel electrophoresis}

Profiling of spermathecal fluid proteins was performed by SDS-PAGE using either Biorad Criterion precast gels (10 to $20 \%(\mathrm{w} / \mathrm{v}$ ) acrylamide, $\mathrm{HCl}, 1 \mathrm{~mm}, 18 \mathrm{comb})$ or larger $12 \%$ (w/v) acrylamide homemade slab gels (Hercules, CA, USA). Gels were run at $30 \mathrm{~mA}$, fixed in fixing solution (40\% methanol, 10\% acetic acid) for an hour and stained overnight with colloidal Coomassie blue (G 250). Gels were kept in $0.5 \%$ (v/ v) phosphoric acid at $4^{\circ} \mathrm{C}$ prior to protein identifications using peptide mass spectrometry.

\section{Identification of proteins from gels using tandem mass spectrometry}

Colloidal Coomassie blue stained protein spots were cut from gels and destained twice in $10 \mathrm{mM} \mathrm{Na}_{2} \mathrm{HCO}_{3}$ with $50 \%$ (v/v) acetonitrile. Samples where dried at $50^{\circ} \mathrm{C}$ before being rehydrated with $15 \mu$ of digestion solution (10 $\mathrm{mM} \mathrm{NH}_{4} \mathrm{CO}_{3}$ with $12.5 \mu \mathrm{g} / \mathrm{ml}$ trypsin (Invitrogen, Carlsbad, CA, USA) and $0.01 \%(\mathrm{v} / \mathrm{v})$ trifluoroacetic acid) and incubated over night at $37^{\circ} \mathrm{C}$. Peptides produced from trypsinization were twice extracted from gel plugs using $15 \mu$ l acetonitrile. The supernatant was then collected and plugs washed twice with $15 \mu \mathrm{l}$ of $50 \%(\mathrm{v} / \mathrm{v})$ acetonitrile and $5 \%(\mathrm{v} / \mathrm{v})$ formic acid and combined with initial supernatant. The pooled extracts were dried by vacuum centrifugation and stored at $4^{\circ} \mathrm{C}$ before being analyzed by mass spectrometry.

\section{Gel spot protein identifications}

Samples from excised gel pieces were analyzed on an Agilent XCT Ultra IonTrap mass spectrometer with an electrospray ionization (ESI) source equipped with a low flow nebuliser in positive mode and controlled by Chemstation (rev. B.01.03 [204]; Agilent Technologies, Santa Clara, CA, USA) and MSD Trap Control software version 6.1 (Bruker Daltonik GmbH, Bremen, Germany). Peptides were eluted from a self-packed Microsorb (Varian Inc., Palo Alto, CA, USA) C18 (5 $\mu \mathrm{m}, 100$ $\AA$ ) reverse phase column $(0.5 \times 50 \mathrm{~mm})$ using an Agilent Technologies 1100 series capillary liquid chromatography system at $10 \mu \mathrm{l} /$ minute using a 9 minute acetonitrile gradient ( 5 to $60 \%(\mathrm{v} / \mathrm{v})$ ) in $0.1 \%(\mathrm{v} / \mathrm{v})$ formic acid at a regulated temperature of $50^{\circ} \mathrm{C}$. The method used for initial ion detection utilized a mass range of 200 to $1,400 \mathrm{~m} / \mathrm{z}$ with scan mode set to 'standard' (8,100 $\mathrm{m} / \mathrm{z}$ per second) and ion charge control conditions set at 250,000 and 3 averages taken per scan. Smart mode parameter settings were employed using a target of $800 \mathrm{~m} / \mathrm{z}$, a compound stability factor of $90 \%$, a trap drive level of $80 \%$ and optimize set to 'normal'. Ions were selected for MS/MS after reaching an intensity of 80,000 cps and two precursor ions were selected from the initial mass spectrometry scan. MS/MS conditions employed SmartFrag for ion fragmentation, a scan range of 70 to $2,200 \mathrm{~m} / \mathrm{z}$ using an average of 3 scans, the exclusion of singly charged ions option and ion charge control conditions set to 200,000 in Ultra scan mode (26,000 m/z per second). Resulting MS/MS spectra were exported from the DataAnalysis for LC/MSD Trap version 3.3 (build 149) software package (Bruker Daltonik 
$\mathrm{GmbH}$ ) using default parameters for AutoMS(n) and compound 'export'. The resulting .mgf files were then searched as outlined below.

\section{Whole lysate protein identifications}

Spermathecal fluid proteins of mated as well as virgin queens were also analyzed with a non-gel approach, using complex mixture LC-MS/MS analysis. Spermathecal samples were digested overnight at $37^{\circ} \mathrm{C}$ with trypsin and insoluble components were removed by centrifugation at $20,000 \times \mathrm{g}$ for 10 minutes. Samples were analyzed on an Agilent 6510 triple quadrupole mass spectrometer (Q-TOF) mass spectrometer with an HPLC Chip Cube source. The chip consisted of a $40 \mathrm{nl}$ enrichment column (Zorbax 300SB-C18 $5 \mathrm{u}$ ) and a $150 \mathrm{~mm}$ separation column (Zorbax 300SB-C18 $5 \mathrm{u}$ ) driven by Agilent Technologies 1100 series nano/capillary liquid chromatography system. Both systems were controlled by MassHunter Workstation Data Acquisition for Q-TOF (version B.01.02, build 65.4, Patches 1,2,3,4; Agilent Technologies). Peptides were loaded onto the trapping column at $4 \mu \mathrm{l} \mathrm{min}{ }^{-1}$ in $5 \%(\mathrm{v} /$ v) acetonitrile and $0.1 \%(v / v)$ formic acid with the chip switched to enrichment and using the capillary pump. The chip was then switched to separation and peptides eluted during a $1 \mathrm{~h}$ gradient ( $5 \%$ acetonitrile to $40 \%$ acetonitrile) directly into the mass spectrometer. The mass spectrometer was run in positive ion mode and scans run over a range of 275 to $1,500 \mathrm{~m} / \mathrm{z}$ and at 4 spectra $\mathrm{s}^{-1}$. Precursor ions were selected for auto MS/MS at an absolute threshold of 500 and a relative threshold of 0.01 , with a maximum of 3 precursors per cycle, and active exclusion set at 2 spectra and released after 1 minute. Precursor charge-state selection and preference was set to $2+$ and then $3+$ and precursors selected by charge then abundance. Resulting MS/MS spectra were opened in MassHunter Workstation Qualitative Analysis (version B.01.02, build 1.2.122.1, Patches 3; Agilent Technologies) and MS/MS compounds detected by 'Find Auto MS/MS' using default settings. The resulting compounds were then exported as mzdata files that were then searched as outlined below.

\section{Database searching}

Mass spectra output files were analyzed against the predicted A. mellifera peptide set (PreRelease2, 11,069 sequences; 5,989,390 residues) from BeeBase [50] using the Mascot search engine version 2.2.03 (Matrix Science, Boston, MA, USA). Gel spot searches were conducted using the Mascot search engine version 2.2.03 (Matrix Science) utilizing error tolerances of \pm 1.2 Da for MS and $\pm 0.6 \mathrm{Da}$ for MS/MS, 'Max missed cleavages' set to 1 , the Oxidation (M) variable modifications and the instrument set to ESI-TRAP and peptide charge set at ' $2+$ and $3+$ '. Results were filtered using 'Standard scoring', 'Max. number of hits' set to 20, 'Significance threshold' at $P<0.05$. Complex lysate searches were conducted using the Mascot search engine version 2.2.03 (Matrix Science) utilizing error tolerances of $\pm 100 \mathrm{ppm}$ for MS and \pm 0.5 Da for MS/MS, 'Max missed cleavages' set to 1, the Oxidation (M) variable modifications and the instrument set to
ESI-Q-TOF and peptide charge set at 2+ and 3+. Results were filtered using 'MUDPIT scoring', 'Max. number of hits' set to 20, 'Significance threshold' at $P<0.05$. Lists of the spermathecal fluid protein sets identified for the various samples and scores for matches are provided as Additional data file 1. To build the protein list, we applied conservative approaches to minimize false positives. Protein matches were only claimed if at least two distinct peptides were detected per protein, and MOWSE (molecular weight search) scores being higher than $50(P<0.05$ significance level is a score $>37)$. False discovery rate analysis of the trypsin digested spermathecal fluid samples from virgin and mated queens against a decoy randomized A. mellifera protein set (PreRelease2, 11,069 sequences; 5,989,390 residues) revealed a $<2.5 \%$ false discovery rate for the virgin queen sample and a $<2.5 \%$ false discovery rate for the sample from mated queens.

Each protein sequence identified from the Apis protein set was submitted to a BLAST search to identify homologous proteins from insects and other organisms. This process was used to confirm or modify the functional annotation of the proteins from the PreRelease 2 dataset, and then each protein was placed into a functional category according to its annotation and manual literature searches where necessary.

\section{Network analysis and visualization}

From the KEGG database [36,37] of biochemical pathways, proteins identified in the present study (Table 1) and [19] were associated with unique ID 'dame' entries specific to $A$. mellifera enzymes. Following this step, enzyme commission (EC) numbers, enzyme names and reactions associated with these KEGG IDs, where these exist, were extracted with a Perl script from the 'enzyme' file downloaded from the KEGG ftp site [51]. Proteins for which no EC number could be assigned typically have unknown function or are responsible for nonenzymatic processes. A total of 41 of the honey bee proteins (using the PreRelease2 accession numbers) in our spermathecal set shown in Table 1 were assigned EC numbers in this manner, making a non-redundant set of 33 enzyme nodes and 70 metabolites. Similarly, seminal fluid proteins from [19] yielded a non-redundant set of 16 enzyme nodes and 47 metabolites.

After the recovery of these data, the set of unique EC numbers and biochemical reactions was parsed to generate a simple interaction format (SIF) file to represent a metabolic network. The SIF file and other data, such as GB codes associated with EC numbers, enzyme names, and node types (enzyme or metabolite), were inputted into the Cytoscape software (version 2.6.0) [32] for network visualization and analysis. Network images were exported from Cytoscape as .svg files, imported into Adobe Illustrator and modified visually for presentation purposes. 


\section{Abbreviations}

EC: Enyme Commission; ESI: electrospray ionization; KEGG: Kyoto Encyclopedia of Genes and Genomes; LC: liquid chromatography; MOWSE: molecular weight search; MS: mass spectrometry; MS/MS: tandem mass spectrometry; NCBI: National Center for Biotechnology Information; QTOF: triple quadrupole mass spectrometer.

\section{Authors' contributions}

BB carried out the experimental work, analyzed the data and wrote the paper; HE participated in the SDS PAGE work and MS/MS; NLT performed all MS/MS runs, NOT performed the network analysis and AHM analyzed the data and cowrote the paper. All authors read and approved the final manuscript.

\section{Additional data files}

The following additional data are available with the online version of this paper: a table showing identification of proteins in honeybee spermathecal fluid by MS/MS analysis of two one-dimensional gels and two gel-free analyses of tryptic peptides (Additional data file 1); a table listing peptide counts from mated and virgin spermathecal fluid using tandem MS analysis of gel-free analyses of tryptic peptides (Additional data file 2); a figure illustrating the metabolic network of seminal and spermatecal fluid (Additional data file 3); a table listing abundances of Drosophila transcripts with sequence similarity to the proteins found in Apis spermatheca (Additional data file 4).

\section{Acknowledgements}

We were supported by the Australian Research Council (ARC) Discovery Program (Queen Elizabeth II Fellowship to BB, Australian Post-doctoral Fellowships to HE and NLT, Australian Professorial Fellowship to AHM) and the ARC Centre of Excellence in Plant Energy Biology (CE056 1495). We thank the honeybee keepers of Western Australia (Better Bees of Western Australia) and especially Ron Clark for providing the necessary honeybee material for this study.

\section{References}

I. Birkhead TR, Moller AP: Sperm Competition and Sexual Selection New York: Academic Press; 1998.

2. Eberhard WG: Sexual Selection and Animal Genitalia Cambridge, Massachusetts: Harvard University Press; 1985.

3. Eberhard WG: Female Control: Sexual Selection by Cryptic Female Choice Princeton, New Jersey: Princeton University Press; 1996.

4. Ruttner F, Koeniger G: The filling of the spermatheca of the honey bee queen active migration or passive transport of the spermatozoa. Z vergl Physiol 1971, 72:4 I I-422.

5. Klenk M, Koeniger G, Koeniger N, Fasold H: Proteins in spermathecal gland secretion and spermathecal fluid and the properties of a $29 \mathrm{kDa}$ protein in queens of Apis mellifera. Apidologie 2004, 35:37I-38I.

6. den Boer SP, Boomsma J, Baer B: Seminal fluid enhances sperm viability in the leafcutter ant Atta colombica. Behav Ecol Sociobiol 2008, 62:1843-1849.

7. den Boer SP, Boomsma JJ, Baer B: Honey bee males and queens use glandular secretions to enhance sperm viability before and after storage. J Insect Physiol 2009, 55:538-543.
8. Collins AM, Williams V, Evans JD: Sperm storage and antioxidative enzyme expression in the honey bee, Apis mellifera. Insect Mol Biol 2004, I 3: |4 |-146.

9. Verma LR: An ionic basis for a possible mechanism of sperm survival in the spermatheca of the queen honey bee Apis mellifera. Comp Biochem Physiol 1973, 44:1325-I33I.

10. Gessner B: Transfer der Spermatozoen in die Spermatheca der Koenigin bei Apis mellifica carnica Frankfurt am Main: Johann Wolfgang Goethe Universität; 1973.

II. Baer B, Armitage SAO, Boomsma JJ: Sperm storage induces an immunity cost in ants. Nature 2006, $441: 872-875$.

12. Simmons LW: Sperm Competition and Its Evolutionary Consequences in the Insects Oxford: Princeton University Press; $200 \mathrm{I}$.

13. Tozetto SDO, Bitondi MMG, Dallacqua RP, Simoes ZLP: Protein profiles of testes, seminal vesicles and accessory glands of honey bee pupae and their relation to the ecdysteroid titer. Apidologie 2007, 38: I- I I.

14. Ram KR, Wolfner MF: Seminal influences: Drosophila Acps and the molecular interplay between males and females during reproduction. Integr Comp Biol 2007, 47:427-445.

15. Poiani A: Complexity of seminal fluid: a review. Behav Ecol Sociobiol 2006, 60:289-310.

16. Baer B: Bumblebees as model organisms to study male sexua selection in social insects. Behav Ecol Sociobiol 2003, 54:521-533.

17. Findlay GD, Yi X, Maccoss MJ, Swanson WJ: Proteomics reveals novel Drosophila seminal fluid proteins transferred at mating. PLOS Biol 2008, 6:el78.

18. Pilch B, Mann M: Large-scale and high-confidence proteomic analysis of human seminal plasma. Genome Biol 2006, 7:R40.

19. Baer B, Heazlewood JL, Taylor NL, Eubel H, Millar AH: The seminal fluid proteome of the honeybee Apis mellifera. Proteomics 2009, 9:2085-2097.

20. Collins AM, Caperna TJ, Williams V, Garett WM, D EJ: Proteomic analyses of male contributions to honeybee sperm storage and mating. Insect Mol Biol 2006, I 5:54 I-549.

21. Colonello NA, Hartfelder K: She's my girl - male accessory gland products and their function in the reproductive biology of social bees. Apidologie 2005, 36:23I-244.

22. Chen PS, Stumm Zollinger E, Aigaki T, Balmer J, Bienz M, Bohlen P: A male accessory gland peptide that regulates reproductive behavior of female Drosophila melanogaster. Cell 1988 , 54:291-298.

23. Baer B, Morgan ED, Schmid-Hempel P: A non-specific fatty acid within the bumblebee mating plug prevents females from remating. Proc Natl Acad Sci USA 200I, 98:3926-3928.

24. Baer B, Maile R, Schmid-Hempel P, Morgan ED, Jones GR: Chemistry of a mating plug in bumblebees. J Chem Ecol 2000, 26: $1869-1875$.

25. Sauter A, Brown MJF, Baer B, Schmid-Hempel P: Males of social insects can prevent queens from multiple mating. Proc $R$ Soc B 200I, 268: |449-|454.

26. Pamilo P: Life span of queens in the ant Formica exsecta. Insect Soc 1991, 38: II1-120.

27. Keller L, Genoud M: Extraordinary lifespans in ants: a test of evolutionary theories of ageing. Nature 1997, 389:958-960.

28. Baer B, Dijkstra MB, Mueller UG, Nash DR, Boomsma إل: Sperm length evolution in the fungus growing ants. Behav Ecol 2009, 20:38-45.

29. Baer B: Sexual selection in Apis bees. Apidologie 2005, 36: $187-200$

30. Boomsma J, Baer B, Heinze J: The evolution of male traits in social insects. Annu Rev Entomol 2005, 50:395-420.

31. Weber NA: Gardening Ants: the Attines Philadelphia: The American Philosophical Society; 1972.

32. Shannon P, Markiel A, Ozier O, Baliga NS, Wang JT, Ramage D, Amin $\mathrm{N}$, Schwikowski B, Ideker T: Cytoscape: a software environment for integrated models of biomolecular interaction networks. Genome Res 2003, 13:2498-2504.

33. Baer B, Schmid-Hempel P: Sperm influences female hibernation success, survival and fitness in the bumblebee Bombus terrestris. Proc R Soc B 2005, 272:319-323.

34. Weinstock GM, Robinson GE, Gibbs RA, Worley KC, Evans JD, Maleszka R, Robertson HM, Weaver DB, Beye M, Bork P, Elsik CG, Hartfelder K, Hunt GJ, Zdobnov EM, Amdam GV, Bitondi MMG, Collins AM, Cristino AS, Lattorff HMG, Lobo $\mathrm{CH}$, Moritz RFA, Nunes FMF, Page RE, Simoes ZLP, Wheeler D, Carninci P, Fukuda S, Hayashizaki Y, Kai C, Kawai J, et al.: Insights into social insects from the genome of the honeybee Apis mellifera. Nature 2006 , 
443:93।-949.

35. Chan QWT, Howes CG, Foster LJ: Quantitative comparison of caste differences in honeybee hemolymph. Mol Cell Proteomics 2006, 5:2252-2262.

36. Kyoto Encyclopedia of Genes and Genomes [http:// www.genome.jp/kegg/]

37. Kanehisa M, Araki M, Goto S, Hattori M, Hirakawa M, Itoh M, Katayama T, Kawashima S, Okuda S, Tokimatsu T, Yamanishi Y: KEGG for linking genomes to life and the environment. Nucleic Acids Res 2008, 36:D480-D484.

38. Cytoscape [http://www.cytoscape.org]

39. Lensky $\mathrm{Y}$, Schindler $\mathrm{H}$ : Motility and reversible inactivation of honeybee spermatozoa in vivo and in vitro. Ann Abeille 1967, 10:5-16.

40. Huss M, Holme P: Currency and commodity metabolites: their identification and relation to the modularity of metabolic networks. IET Syst Biol 2007, I :280-285.

4I. Prokupek A, Hoffmann F, Eyun SI, Moriyama E, Zhou M, Harshman L: An evolutionary expressed sequence tag analysis of Drosophila spermathecal genes. Evolution 2008, 62:2936-2947.

42. Allen AK, Spradling AC: The SfI-related nuclear hormone receptor Hr39 regulates Drosophila female reproductive tract development and function. Development 2008, I 35:31|-32|.

43. FlyAtlas: the Drosophila Gene Expression Atlas [http:// www.flyatlas.org]

44. Chintapalli VR, Wang J, Dow JAT: Using FlyAtlas to identify better Drosophila melanogaster models of human disease. Nat Genet 2007, 39:715-720.

45. Stevens TH, Forgac M: Structure, function and regulation of the vacuolar (H+)-ATPase. Annu Rev Cell Dev Biol 1997, I3:779-808.

46. Nelson N, Harvey WR: Vacuolar and plasma membrane proton-adenosinetriphosphatases. Physiol Rev 1999, 79:36I-385.

47. Verma LR, Shuel RW: Respiratory metabolism of the semen of the honeybee, Apis mellifera. J Insect Physiol 1973, 19:97-I03.

48. Gessner B, Ruttner F: Transfer of spermatozoa into the spermatheca of the honey bee queen. Apidologie 1977, 8: I- I8.

49. Kunieda T, Fujiyuki T, Kucharski R, Foret S, Ament SA, Toth AL, Ohashi K, Takeuchi H, Kamikouchi A, Kage E, Morioka M, Beye M, Kubo T, Robinson GE, Maleszka R: Carbohydrate metabolism genes and pathways in insects: Insights from the honey bee genome. Insect Mol Biol 2006, I 5:563-576.

50. BeeBase: Hymenoptera Genome Database [http://www.bee base.org]

51. Kegg FTP Site [ftp://ftp.genome.jp/pub/kegg/ligand/enzyme/ enzyme]

52. TargetP I.I Server [http://www.cbs.dtu.dk/services/TargetP/]

53. Psort Site [http://psort.ims.u-tokyo.ac.jp/] 